
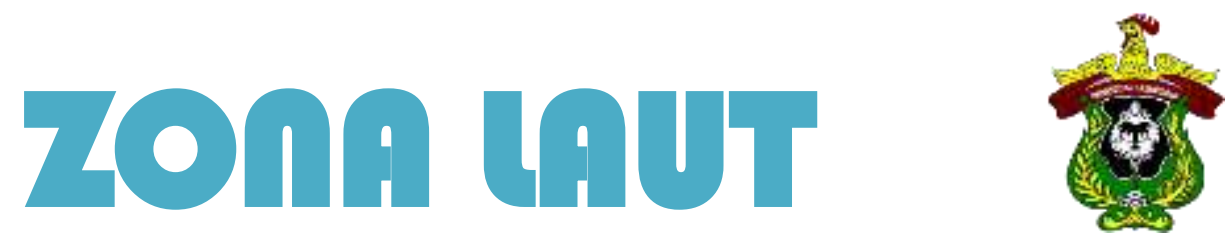

\title{
KAJIAN KEGAGALAN DAN PERAWATAN PADA SISTEM PELUMAS MESIN DIESEL DI KAPAL
}

\author{
*Ratna Indriyani dan Dwisetiono \\ Jurusan Teknik Sistem Perkapalan Universitas Hang Tuah \\ *indriyaniratna082@gmail.com
}

\begin{abstract}
Abstrak
Mesin diesel sebagai mesin induk di kapal dapat berfungsi dengan baik apabila ditunjang oleh sistem-sistem pendukung yang baik seperti sistem pelumas (lubricating oil system). Sistem pelumas salah satu sistem yang sangat penting dalam pengoperasian kapal, kegagalan pada sistem pelumasan menyebabkan sistem tidak beroperasi semestinya dan dapat mengalami kerugian dari pihak kapal. Kajian ini bertujuan untuk mengetahui kagagalan pada setiap komponen sistem pelumas di main engine dan perawatan yang tepat. Kajian ini dilakukan dengan menggunakan metode Failure Mode and Effect Analysis (FMEA) untuk mengoptimalkan cara mengatasi kegagalan dan perawatan mesin utama kapal untuk mengidentifikasi strategi dan prioritas perawatan. Dengan menggunakan FMEA dapat mengetahui kegagalan serta efek yang ditimbulkan oleh tiap-tiap komponen dapat diketahui dan untuk melakukan perawatan harus mengelompokan komponen berdasarkan tingkat resiko rendah sampai tinggi. Komponen lubricating oil tank dan sump tank memiliki resiko yang rendah, lubricating oil cooler memiliki resiko sedang dan lubricating oil pump, lubricating oil filter, purifier, transfer pump dan lubricating purifier heater memiliki resiko tinggi. Hasil dari kegagalan komponen sistem pelumas sangat berguna untuk mengidentifikasi strategi perawatan berdasarkan tingkat resiko komponen tersebut dengan memilih antara perawatan pencegahan (preventive maintenance) dan perawatan korektif (corrective maintenance).
\end{abstract}

Kata Kunci: Kegagalan, Sistem Pelumas, Perawatan, FMEA.

\begin{abstract}
Abstrct
The diesel engine as the main engine on the ship can function properly if it is supported by good supporting systems such as a lubricating oil system. The lubricant system is one of the most important systems in ship operation, failure in the lubrication system causes the system to not operate properly and can suffer losses from the ship. This study aims to determine the failure of each component of the lubricating system in the main engine and its proper maintenance. This study was conducted using the Failure Mode and Effect Analysis (FMEA) method to optimize the way to overcome the failure and maintenance of the ship's main engines to identify strategies and maintenance priorities. By using FMEA, we can determine the failure and the effect caused by each component and to perform maintenance must classify components based on low to high-risk levels. The components of a lubricating oil tank and sump tank have a low risk, lubricating oil cooler has a moderate risk and lubricating oil pump, lubricating oil filter, purifier, transfer pump and lubricating purifier heater have a high risk. The results of the failure of lubricant system components are very useful in identifying maintenance strategies based on the level of risk of these components by choosing between preventive maintenance and corrective maintenance.
\end{abstract}

Keyword: Failure, Lubricating System, Maintenance, FMEA.

\section{PENDAhUlan}

Dengan berkembangnya transportasi laut semakin banyak kapal yang beroperasi sehingga keberadaan mesin diesel sebagai penggerak utama memegang peranan penting dalam sistem permesinan, mesin utama di kapal harus bekerja terus menerus saat dioperasikan [1]. Mesin diesel di kapal dapat berfungsi dengan baik apabila ditunjang oleh sistem-sistem pendukung yang baik pula. Salah satu faktor pendukung untuk kelancaran copyright is published under Lisensi Creative Commons Atribusi 4.0 Internasional. 
jalannya mesin diesel yaitu sistem pelumas, kurangnya pelumasan pada mesin diesel ini akan berdampak gesekan antar bagian-bagian apabila hal ini terjadi maka akan menyebabkan gangguan pengoperasian kapal. Fungsi dari suatu sistem pelumasan adalah untuk menyediakan jumlah minyak pelumas yang cukup dan dingin serta bersih ke dalam mesin untuk mengadakan pelumasan yang efektif dan cukup terhadap semua bagian yang saling bergesekan dan bergerak yang terjadi di dalam mesin itu sendiri [2]. Setiap sistem tersebut memiliki fungsi serta fungsi yang sangat penting, apabila terjadi kegagalan pada salah satu sistem penunjangnya maka dapat mempengaruhi kinerja motor induk secara keseluruhan.

Kegagalan (failure) yang terjadi pada salah satu komponen sistem pelumas dapat menimbulkan suatu kegagalan yang sifatnya merusak keseluruhan fungsi kapal pada akhirnya akan mengakibatkan kerugian besar dan menjadi risiko yang pasti dialami oleh sistem pelumas. Kegagalan juga menjadi hal terpenting dalam memprediksi suatu sistem pada masa yang akan datang serta efek yang akan ditimbulkan terhadap komponen sistem lain. Kegagalan dan perbaikan merupakan hal yang terpenting dalam memprediksi suatu sistem pada masa yang akan datang serta efek yang akan ditimbulkan terhadap komponen lain apabila komponen tersebut prilaku dari suatu sistem pada masa yang akan datang serta efek yang akan ditimbulkan terhadap komponen lain apabila komponen tersebut gagal beroperasi [3].

Failure Mode and Effect Analysis (FMEA) sebuah teknik rekayasa yang digunakan untuk menetapkan, mengidentifikasi, dan untuk menghilangkan kegagalan yang diketahui, permasalahan, error, dan sejenisnya dari sebuah sistem, desain, proses, dan jasa sebelum mencapai konsumen [4]. Kajian ini untuk mengetahui kegagalan setiap komponen sistem pelumas di mesin diesel dan memilih jenis perawatan yang tepat untuk komponen. Manfaat mengetahui kegagalan dan perawatan koponen sistem pelumas akan memberikan keuntungan kepada pihak kapal dalam hal maintenance.

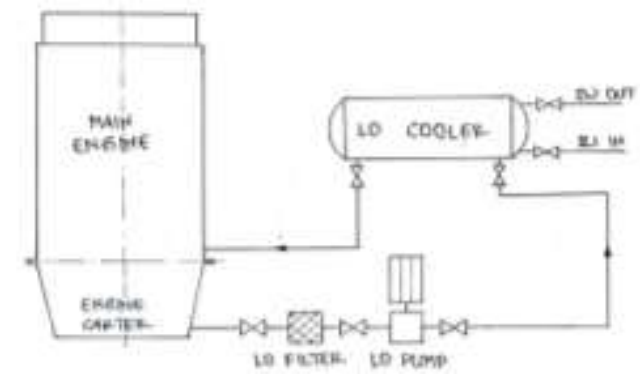

Gambar 1. Pelumasan basah

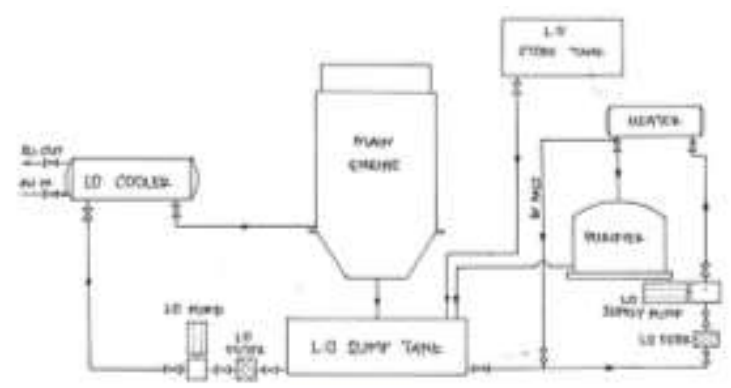

Gambar 2. Pelumasan kering

\section{METODE}

Salah satu faktor pendukung untuk kelancaran pengeoperasian mesin diesel salah satunya yaitu sistem pelumas, kurangnya pelumasan pada mesin diesel ini akan mengganggu pengoperasian kapal secara keseluruhan. Kegagalan komponen pada sistem pelumas akan berdampak pada pengoperasian maka diperlukan kajian untuk mengatasi kegagalan dari setiap komponennya dan perawatan komponen berdasarkan tingkat resiko. Metode yang digunakan dalam kajian ini adalah Failure Mode and Effect Analysis (FMEA) dan pemilihan perawatan berdasarkan matriks resiko. Tujuan dari kajian ini untuk mengetahui komponen yang mengalami kegagalan pada sistem pelumas di mesin diesel dan pemilihan perawatan berdasarkan tingkat resiko kegagalannya. Flow chart penelitian ini ditampilakan pada gambar berikut. 


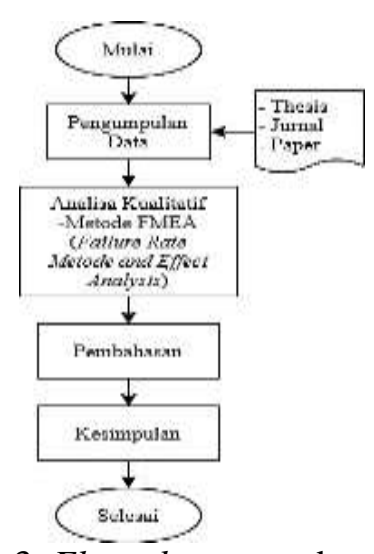

Gambar 3. Flow chart metode penelitian

\subsection{Analisa Kualitatif}

Analisa kualitatif merupakan analisa yang digunakan untuk mengevaluasi keandalan suatu sistem berdasarkan analisa kegagalan, sehingga kita dapat melakukan penilaian keandalan berdasarkan data kualitatif. Dalam analisa kualitatif untuk mengevaluasi keandalan suatu sistem digunakan metode Failure Mode and Effect Analysis (FMEA). Failure modes and effect analysis adalah analisa teknik yang apabila dilakukan dengan tepat dan waktu yang tepat akan memberikan nilai yang besar dalam membantu proses pembuatan keputusan dari engineer selama perancangan dan pengembangan. Analisa tersebut biasa disebut analisa "bottom up", seperti dilakukan pemeriksaan pada proses produksi tingkat awal dan mempertimbangkan kegagalan sistem yang merupakan hasil dari keseluruhan bentuk kegagalan yang berbeda.

\subsection{Pemilihan Perawatan}

Pemilihan perawatan berdasarkan metode Failure Mode and Effect Analysis (FMEA), dapat mengetahui kegagalan dari komponen-komponen yang terdapat di sistem sehingga dapat memilih perawatan yang tepat dan sesuai berdasarkan tingkat kegagalan dari sistem tersebut dengan memilih antara perawatan pencegahan (preventive maintenance) dan perawatan korektif (corrective maintenance).

\section{HASIL DAN PEMBAHASAN}

Definisi dari sistem pelumasan adalah sistem yang berfungsi untuk mensuplai minyak pelumas yang berasal dari service tank menuju main engine. Berikut merupakan komponen yang ada pada sistem minyak pelumas antara lain lubricating oil tank, transfer pump, sump tank, LO. separator, purifier, LO. cooler, filter, LO pump kemudian menuju main engine, dan Lubricating Purifier Heater.

Berikut komponen sistem pelumasan (Lubricating Oil System) dan fungsinya di kapal antara lain:

Tabel 1. Fungsi dari komponen sistem pelumas

\begin{tabular}{cll}
\hline No & Nama Komponen & Fungsi \\
\hline 1 & Lubricating oil tank & $\begin{array}{l}\text { Berfungsi tempat penyimpanan minyak pelumas awal sebelum di } \\
\text { suplai ke sump tank. }\end{array}$ \\
\hline 2 & Lubricating oil pump & $\begin{array}{l}\text { Berfungsi untuk memompa minyak pelumas yang berasal dari sump } \\
\text { tank menuju main engine. Terdapat dua buah lubricating oil pump } \\
\text { yang dipasang secara standby. }\end{array}$ \\
\hline 3 & Lubricating oil cooler & $\begin{array}{l}\text { Berfungsi untuk mendinginkan oli yang keluar dari mesin Induk atau } \\
\text { mesin bantu dengan pendinginan air laut. }\end{array}$ \\
\hline 4 & Filter & $\begin{array}{l}\text { Berfungsi untuk menyaring minyak pelumas dari daily tank agar } \\
\text { minyak pelumas yang di suplai ke main engine benar-benar bersih. } \\
\text { Terdapat dua buah filter yang dipasang secara standby. }\end{array}$ \\
\hline 5 & Sump tank & $\begin{array}{l}\text { Berfungsi sebagai tempat pengendapan kandungan air dan kotoran } \\
\text { yang terdapat pada minyak pelumas. }\end{array}$ \\
\hline
\end{tabular}




\begin{tabular}{cll}
\hline No & Nama Komponen & Fungsi \\
\hline 6 & Separator & $\begin{array}{l}\text { Berfungsi untuk membersihkan dan memurnikan minyak pelumas dari } \\
\text { pengaruh kandungan air dan kontaminasi partikel padat. Terdapat dua } \\
\text { buah separator yang dipasang secara standby. }\end{array}$ \\
\hline 7 & Transfer Pump & $\begin{array}{l}\text { Berfungsi untuk memindahkan minyak pelumas dari service tank } \\
\text { menuju sump tank. Terdapat dua buah transfer pump yang disusun } \\
\text { secara standby. }\end{array}$ \\
\hline 8 & $\begin{array}{l}\text { Lubricating Purifier } \\
\text { Heater }\end{array}$ & $\begin{array}{l}\text { Berfungsi untuk meningkatkan temperature serta viskositas minyak } \\
\text { pelumas. }\end{array}$ \\
\hline
\end{tabular}

Prinsip kerja sistem minyak pelumas sebagai berikut: minyak pelumas dari service tank dipindahkan ke sump tank dengan bantuan transfer pump. Di dalam sump tank minyak pelumas diendapkan dari air dan kotoran padat. Setelah itu dialirkan menuju separator. Melalui separator minyak pelumas dimurnikan dan dibersihkan terlebih dahulu dari kandungan air dan kontaminasi kandungan partikel padat. Sebelum menuju main engine minyak pelumas disaring dan dibersihkan menggunakan purifier. Selanjutnya minyak pelumas dialirkan menuju main diesel engine melalui filter dan lubricating oil cooler. Temperatur oil keluar dari cooler secara otomatis dikontrol pada level konstan yang ditentukan untuk memperoleh viskositas yang sesuai dengan yang diinginkan pada inlet main diesel engine. Kemudian lubricating oil dialirkan ke main engine bearing dan juga dialirkan kembali ke lubricating oil sump tank.

Analisa kualitatif menggunakan metode Failure Mode and Effect Analysis (FMEA) adalah metode yang sistematis dalam menganalisa suatu bentuk kegagalan dan penekanannya pada bottom-up approach. Maksud dari bottom-up approach adalah teknik analisa yang dilakukan mulai dari peralatan/ komponen dan kemudian meneruskannya ke dalam sistem yang mempunyai level lebih tinggi. Tujuan dari FMEA adalah mendapatkan komponen yang paling kritis terhadap kegagalan sistem minyak pelumas. Didalam metode FMEA ini hal-hal yang harus dilakukan adalah mereview berbagai komponen, subsistem dan juga mengidentifikasi mode-mode kegagalan, penyebab kegagalan serta efek dan dampak dari kegagalan yang ditimbulkan. Berikut gambar diagram Failure Mode and Effect Analysis (FMEA) padapenelitian ini.

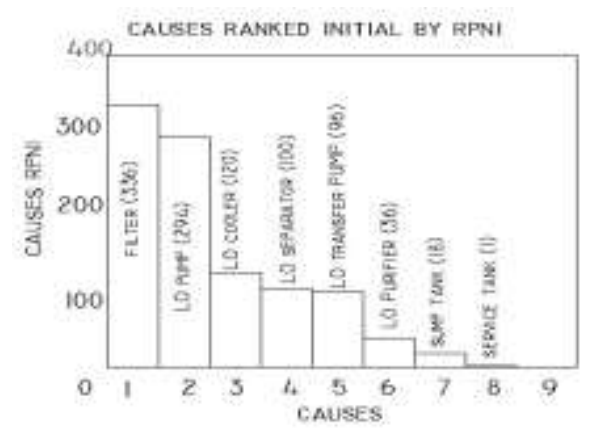

Gambar 4. Diagram Failure Mode and Effect Analysis (FMEA)

Melakukan identifikasi terhadap masing-masing komponen dari sistem pelumasan. Identifikasi mode kegagalan yang terjadi. Dampak yang dapat ditimbulkan karena adanya kegagalan sistem dimana dibagi menjadi 3 bagian yaitu local effect, next higher effect dan end effect [4]. Berdasarkan atas kegagalan yang terjadi akan diberikan solusi atau cara yang digunakan untuk mengatasi kegagalan dari masing-masing komponen tersebut. Identifikasi tersebut dilakukan dengan menggunakan tabel Failure Mode And Effects Analysis (FMEA).

Tabel 2. Konsekuensi berdasarkan FMEA

\begin{tabular}{ll}
\hline Nama Komponen & Konsekuensi \\
\hline Lub Oil Tank & Ringan \\
\hline LO. Cooler & Sedang \\
\hline LO. Filter & Berat \\
\hline Sump Tank & Ringan \\
\hline Purifier & Berat \\
\hline Transfer. Pump & Berat \\
\hline Lubricating Purifier Heater & Berat \\
\hline
\end{tabular}


Berdasarkan tabel tersebut dapat diketahui bahwa terdapat 5 komponen yang memiliki konsekuensi yang tinggi, 1 komponen dengan konsekuensi sedang dan 2 komponen memiliki konsekuensi yang rendah. Untuk mengetahui resiko dari setiap komponen maka diperlukan adanya penentuan resiko menggunakan risk matrik.

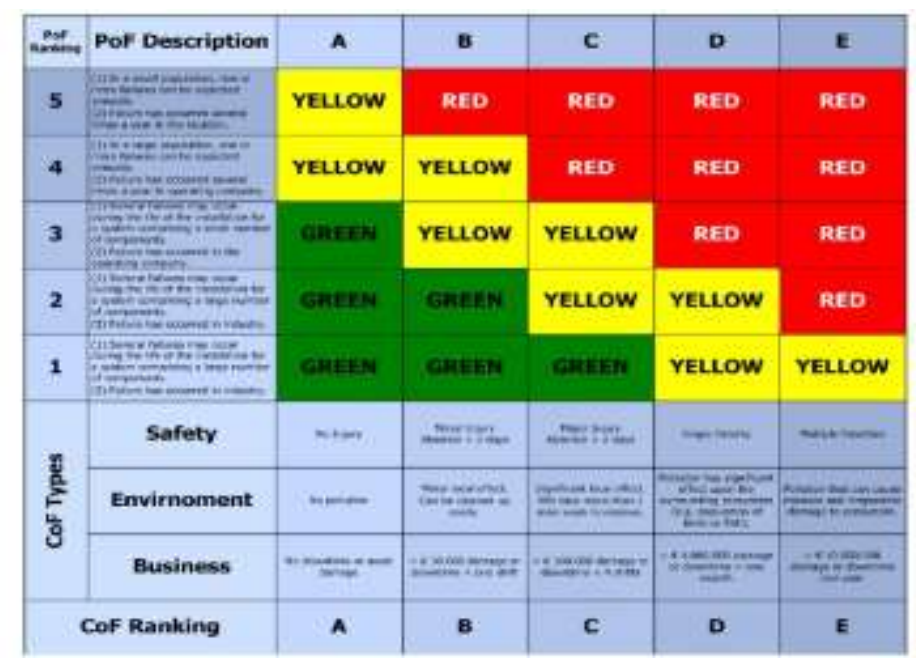

Gambar 5. Matriks resiko

Matriks Resiko menjelaskan hubungan antara konsekuensi dari kegagalan dan probabilitas kegagalan dalam menentukan tingkat resiko. Tingkatan resiko dibuat penandaan dalam warna yaitu: merah untuk resiko tinggi, kuning untuk resiko sedang, dan hijau untuk resiko rendah [5]. Matriks berbasis resiko yang menggunakan tingkat resiko sebagai dasar dalam memprioritaskan suatu aktivitas inspeksi. Untuk mengetahui resiko dari setiap komponen maka diperlukan adanya penentuan resiko menggunakan matrik risk ditandai dengan warna yang berbeda dimana $\mathrm{L}=$ Low risk, $\mathrm{M}=$ Medium risk, dan $\mathrm{H}=$ High risk.

Tabel 3. Frekuensi kegagalan komponen

\begin{tabular}{cll}
\hline No & Nama Komponen & Kemungkinan \\
\hline 1 & Lub Oil Tank & Tidak \\
\hline 2 & LO. Pump & Terjadi \\
\hline 3 & LO. Cooler & Terjadi \\
\hline 4 & LO. Filter & Terjadi \\
\hline 5 & Sump Tank & Tidak \\
\hline 6 & Purifier & Terjadi \\
\hline 7 & Transfer Pump & Terjadi \\
\hline 8 & Lubricating Purifier Heater & Terjadi \\
\hline
\end{tabular}

Berdasarkan tabel tersebut dapat diketahui bahwa terdapat 2 komponen yang kemungkinan mengalami kegagalan yang kecil dan 6 komponen yang kemungkinan mengalami kegagalan yang besar.

Tabel 4. Level risiko komponen

\begin{tabular}{ll}
\hline Nama Komponen & Level resiko \\
\hline Lub Oil Tank & Rendah \\
\hline LO. Cooler & Sedang \\
\hline LO. Filter & Tinggi \\
\hline Sump Tank & Tinggi \\
\hline Purifier & Rendah \\
\hline Transfer. Pump & Tinggi \\
\hline Lubricating Purifier Heater & Tinggi \\
\hline LO. Pump & Tinggi
\end{tabular}

Dengan mengetahui masing-masing kegagalan yang terjadi dari tiap-tiap komponen sistem pelumasan maka dapat dengan mudah melakukan penilaian resiko yang nantinya dapat dijadikan sebagai acuan didalam 
pemilihan metode perawatan. Identifikasi yang telah dilakukan menggunakan FMEA dan risk matrik maka diketahui tingkat kekritisan dari masing-masing komponen dimana: (1) untuk komponen lubricating oil tank dan sump tank memiliki rating risk yang rendah; (2) kemudian untuk komponen lubricating oil cooler memiliki nilai rating mayor; (3) untuk komponen lubricating oil pump, lubricating oil filter, purifier, transfer pump dan lubricating purifier heater memiliki nilai rating risk yang sama yakni high risk. Analisa yang telah dilakukan dengan menggunakan metode Failure Mode and Effect Analysis (FMEA) maka dapat dilihat komponen mana saja yang membutuhkan prioritas yang tinggi untuk kegiatan perawatan pada sistem pelumasan di kapal.

Terdapat beberapa strategi perawatan yang dapat digunakan untuk melakukan evaluasi perawatan yang lebih efektif dan efesien, yaitu (1) Sebaiknya dibuat dan disusun suatu maintenance scheduling secara tepat dan terencana terutama untuk komponen-komponen dengan resiko yang tinggi yang dapat mempengaruhi kinerja sistem secara keseluruhan.2) Menentukan prioritas pekerjaan perawatan berdasarkan tingkat kekritisan komponen. Dalam hal ini yang menjadi prioritas utama adalah komponen dengan level resiko tinggi yaitu diantaranya adalah LO. Pump, LO. Filter, Purifier, Transfer Pump, Lubricating Purifier Heater. (3) Mengidentifikasi kebutuhan suku cadang terutama untuk komponen yang memiliki tingkat kekritisan yang tinggi agar apabila terjadi kegagalan maka tidak sampai mengganggu proses produksi. Perawatan komponen sistem pelumas yang memiliki resiko tinggi meliputi:

1. Memeriksa permukaan gigi-giginya terhadap keausan, gejala kavitasi dan kerusakan lainnya.

2. Memeriksa permukaan kelilingnya terhadap gejala kemacetan, dengan memberikan minyak.

3. Memeriksa apakah porosnya sudah aus. dalam hal ini digunakan serat minyak pelumas, pada umumnya keausan terbesar terdapat pada bagian porosnya yang dikenai sekat tersebut.

4. Memeriksa permukaan kontak poros dengan bantalannya. dalam hal ini dipergunakan bantalan peluru, maka periksalah bantalannya

5. Apabila menggunakan paking, gantilah pakingnya dengan paking yang baru dengan tebal dan dari jenis yang sama, ukurlah dengan teliti.

6. Memeriksa permukaan dalam rumah pompa terhadap kemungkinan korosi, keausan dan kerusakan lainnya.

7. Memeriksa katup pengatur tekanan minyak pelumas terhadap kelainan yang mungkin terjadi pada dudukan katup-katup, jalan katup, dan pegas katup.

\section{KESIMPULAN}

Kegagalan yang terjadi pada komponen dapat menimbulkan suatu kegagalan yang sifatnya merusak keseluruhan fungsi utama kapal khususnya sistem pelumas di main engine. Komponen lubricating oil tank dan sump tank memiliki tingkat kekritisan yang rendah, kemudian untuk komponen lubricating oil cooler memiliki nilai kekritisan sedang dan untuk komponen lubricating oil pump, lubricating oil filter, purifier, transfer pump dan lubricating purifier heater memiliki nilai kekritisan tinggi. Hasil dari kegagalan komponen terhadap sistem pelumas sangat berguna untuk mengidentifikasi strategi perawatan berdasarkan tingkat resiko komponen tersebut dengan memilih antara perawatan pencegahan (preventive maintenance) dan perawatan korektif (corrective maintenance).

\section{DAFTAR PUSTAKA}

[1] Arismunandar, W. dan K. T. (2008) Motor Diesel Putaran Tinggi. Jakarta: Pradnya Paramita.

[2] Danil Arifin, M., Octaviani, F. and Novita, T. D. (2020) 'Analisa Kegagalan Sistem Pelumasan dan Pemilihan Metode Perawatan M/E di Kapal Menggunakan Metode FMEA Dalam Rangka Menunjang Operasi Transportasi Laut di Indonesia', Jurnal Penelitian Transportasi Laut, 17(1), pp. 1-6. doi: 10.25104/transla.v17i1.1416.

[3] Hanif, R. Y., Rukmi, H. S. and Susanty, S. (2015) 'Perbaikan Kualitas Produk Keraton Luxury di PT.X dengan Menggunakan Metode Failure Mode and Effect Analysis (FMEA) dan Fault Tree Analysis (FTA)', Jurnal Online Institut Teknologi Nasional Juli, 03(03), pp. 137-147.

[4] Manalu, R. B. et al. (2016) 'Analisa Perawatan Sistem Distribusi Minyak Lumas Berbasis Keandalan Pada Kapal Km.Bukit Siguntang Dengan Pendekatan Rcm (Reliability Centered Maintenance)', Jurnal Teknik Perkapalan, 4(1).

[5] Yusuf, Z. A. (2016) ‘Analisa Perawatan Berbasis Resiko Pada Sistem Pelumas Km. Lambelu', Jurnal Riset dan Teknologi Kelautan (JRTK), 14(1), pp. 129-140. 